\title{
A perfeita ilusão: as personagens e suas relações em A luz no subsolo
}

\author{
The perfect illusion: the characters and their relationships in A luz no subsolo
}

\author{
LUÍS ALBERTO PAZ* \\ Pontifícia Universidade Católica do Rio Grande do Sul, Porto Alegre, RS, Brasil
}

\begin{abstract}
Resumo: O presente trabalho propõe uma análise do romance $A$ luz no subsolo, de Lúcio Cardoso, lançado em 1936, com base nas teorias do romance, sobretudo no que diz respeito à personagem de ficção. Para o desenvolvimento deste trabalho é elaborada, então, uma revisão teórica a respeito do romance, bem como sobre a importância e o processo de construção das personagens na obra. Da mesma forma, faz-se um levantamento da fortuna crítica relativa ao autor e à obra em questão. Com base nesse procedimento, busca-se compreender o papel fundamental da personagem, e sua rede de relações, no romance de Lúcio Cardoso, e de que forma o universo literário do autor constitui-se para construir um mapa de significações. Com o objetivo de recuperar a visão da crítica a respeito da obra, este trabalho propõe um novo estudo acerca do universo cardosiano. Ao estabelecer um novo olhar sobre a literatura produzida pelo autor, o trabalho também possibilita uma nova repercussão a respeito do conjunto de suas obras, além de instigar a reflexão sobre o lugar deste artista nos estudos acadêmicos.
\end{abstract}

Palavras-chave: Lúcio Cardoso; romance; personagem; rede de relações.

\begin{abstract}
The present work proposes an analysis of the novel A luz no subsolo, written by Lúcio Cardoso, published in 1936, based on the Theories of the Novel, especially regarding the character of fiction. For the development of this work, a theoretical revision regarding the novel is elaborated in conjunction with a revision on the importance and the process of character building in this piece of work. Furthermore, a survey of the critical resources relative to the author and the work in question is made. Based on this procedure, it is sought to understand the fundamental role of the character and his network of relationships in the novel written by Lúcio Cardoso, and how the literary universe of the author is constituted to build a map of meanings. Aiming at recovering a critic vision concerning the novel, this work proposes a new study about the universe of the author. By establishing a new perspective on the literature produced by the author, this work allows a new repercussion regarding his group of work and incites the reflection on the place of this artist in academic studies.
\end{abstract}

Keywords: Lúcio Cardoso; novel; character; network of relationships.

\footnotetext{
* Graduado em Letras (português e suas respectivas literaturas) pela Pontifícia Universidade Católica do Rio Grande do Sul (2017), onde atuou como bolsista de Iniciação Científica no período de 2013 a 2017, tendo participado de pesquisas nas áreas de literatura brasileira autobiográfica e memorialística, e literaturas de língua portuguesa de origens europeia e africana. Atualmente é mestrando em Teoria da Literatura no Programa de Pós-Graduação em Letras da Pontifícia Universidade Católica do Rio Grande do Sul. <luis.alberto@acad.pucrs.br>
} 
O que imploro a quem me ler é que sinta horror diante de mim, se não me compreender. Do contrário eu o mando à merda!

Merda, pois, aos que souberem de mim pela metade, aos que em mim vierem buscar justificação para mentiras!

LÚCIO CARDOSO

Lúcio Cardoso é contemporâneo de renomados escritores como Clarice Lispector e Guimarães Rosa. A maior parte de sua obra foi reconhecida pela crítica, não tendo nenhuma publicação passada despercebida. Entretanto, a historiografia literária, de modo geral, não se preocupou em incluir seu nome entre os dos grandes literatos do país. Com o passar do tempo, sua obra foi abandonada e seu nome pouco citado nos diferentes almanaques literários brasileiros.

Passaram-se mais de cinco décadas desde o lançamento de A crônica da casa assassinada, considerada sua obraprima. Basta realizar uma breve pesquisa sobre a produção acadêmica a respeito do autor para constatar que esta é, ainda, praticamente a única obra que parece receber menção. Mesmo tendo elaborado uma vasta produção artística que consiste em romances, contos, teatro, poesia e artes plásticas, os poucos trabalhos que visam à rememoração da obra cardosiana abordam, quase sempre, este elogiado romance.

A partir do (re) conhecimento destes aspectos acerca da obra de Lúcio Cardoso, o presente trabalho propõe a revisão de um dos romances do autor que marca uma fase de transição em sua carreira. Trata-se de A luz no subsolo, obra que foi muito comentada à época de seu lançamento e dividiu opiniões da crítica. Se, por um lado, Lúcio sinalizava para a complexidade do psicologismo, reflexão da alma e anseios mundanos já em seus primeiros romances (Maleita e Salgueiro), é em A luz no subsolo que ele se firma no campo dos estudos humanos.

O objetivo do trabalho é contribuir para os estudos de literatura brasileira com a retomada da obra de Lúcio Cardoso, provando que A luz no subsolo apresenta um complexo processo de construção das personagens, que resulta na produção intimista e psicológica do romance e, por conseguinte, corrobora com a representação do dilema das relações humanas.

\section{A recepção crítica de $A$ luz no subsolo}

Em sua obra, Lúcio Cardoso cria seres fictícios que representam os anseios e arroubos emocionais - tipicamente humanos - que são alimentados por uma história de atmosfera densa e amarrada. É observável o espaço agindo como continuidade dos desejos e medos das personagens, enquanto o tempo oprime os pensamentos e transforma lucidez em desejos demoníacos. A interiorização dos pesadelos e da incapacidade de mudar a realidade causa nas personagens a dinamicidade das redundâncias humanas presas à concretude da vida. Nas palavras de Philippe Hamon,

Uma personagem é pois o suporte das redundâncias e das transformações semânticas da narrativa, é constituída pela soma das informações facultadas sobre o que ela é e sobre o que ela faz. (HAMON, 1983, p. 20)

Evocando o texto de Muir (1975), pode-se pensar o romance cardosiano como pertencente ao romance dramático, uma vez que suas obras focalizam todos 
os ângulos das personagens, aprofundando seus pensamentos, desejos, anseios, pavores e paixões, e, ao mesmo tempo em que a ação empurra estas personagens ao encontro desses anseios, as personagens conduzem o fluxo narrativo (e o leitor) por um passeio interior, vivo, dinâmico e mutável, imperfeito, constante. A narrativa é progressiva à medida que ação e personagem tornam-se um elemento simbiôntico, quase indissociável e, sobretudo, conveniente - visto que o leitor anda sob o vale das sombras do que lhe é apresentado.

O mundo da ficção mostra-se inteiramente relacionado por padrões de espaço-tempo que provocam reações imediatas nas criaturas. Essa noção de que o ser está inserido num mundo dinâmico e opressor, interligado por uma rede de fios invisíveis que se conectam uns aos outros, entre o passado e o futuro, numa trama indissociável às forças da natureza, revela o protagonismo das personagens no enredo do romance.

Deste modo, é possível pensar que em A luz no subsolo, "o mundo das coisas pode também não ser estranho, oposto à personagem. Pode ser sinal de fraternidade e de espera de um ser" (BOURNNEUF e OUELLET, 1976, p. 203). Traduzível, assim, por exemplo, à relação de Emanuela com as gramas nascentes, os animais que rondam os matos rasteiros, e a noite que é porta para o mundo dos sonhos e desejos.

Paula Francioli de Sousa, em sua dissertação A manifestação do grotesco nos romances de Lúcio Cardoso (2013) diz, a respeito de A luz no subsolo:

Com uma veia profundamente psicológica, todos os personagens, em algum momento do romance, são tomados pela loucura, pelo delírio ou por forças malignas. A narrativa se inicia em clima de mistério e perturbação, que só tende a aumentar com o decorrer da história, sem pausa dramática, chegando ao fim num clima irrespirável, integralmente de loucura, alucinações e existências degradadas. A atmosfera de pesadelo é a manifestação da subjetividade agônica de cada personagem, é o reflexo de suas angústias e tormentos (SOUSA, 2013, p. 76).

Elabora-se um paralelo entre a construção das personagens de seus dois primeiros romances e $A$ luz no subsolo. Nesse sentido, na obra Luz e sombra em Lúcio Cardoso (1997), Maria Terezinha Martins escreve que:

As personagens de Salgueiro estão presas a ele, como acontece também em Maleita. [...] paradoxalmente, a paisagem volta, readquire seu estado original, vale por si mesma.

Diferentemente atua o espaço de $A$ luz no subsolo. [...] ele é similar à noção espacial explorada por Marcel Proust em À sombra das raparigas em flor. Fora da rotina de seu ambiente, justamente por lhe serem estranhos, os objetos que compõem o novo habitat adquirem vida própria e fazem-nos sentir mais intensamente a solidão (MARTINS, 1997, p. 45).

Observado sob este ângulo, o romance de Lúcio Cardoso, publicado em 1936 pela José Olympio, só podia ser alvo de questionamentos e críticas ácidas. É preciso pensar no contexto histórico que Lúcio vivia para se estabelecer um juízo sobre a recepção da crítica de sua obra: em primeiro lugar, Lúcio passou a ser publicado por uma editora renomada e de grande porte. Em segundo lugar, Lúcio já publicara Maleita (1934) e Salgueiro (1935), romances associados à literatura regionalista e urbana, respectivamente. Isso deu a ele 
uma posição célebre de reconhecimento para uma promissora carreira.

Com A luz no subsolo, entretanto, Lúcio Cardoso rompe com a estética da época essencialmente de obras contemporâneas como O quinze, de Rachel de Queiroz, e Menino do engenho, de José Lins do Rego.

$\mathrm{Na}$ dissertação Atmosfera de paixão e tempestade: as dimensões do espaço ficcional na Crônica da casa assassinada, de Lúcio Cardoso, Roberta Alina Boeira Triburri comenta a importância desse terceiro romance do autor tanto para sua vida literária quanto pessoal:

A mudança de rumo da escrita de Lúcio, negando a corrente dos romances de cunho social, e mergulhando completamente no romance introspectivo, abriu espaço para que a crítica atacasse a obra recém-lançada e, consequentemente, seu autor. Lúcio se deixa abater pelas críticas e se afasta temporariamente da literatura, dedicando-se a outras artes, como o teatro e o cinema (TRIBURRI, 2013, p. 16).

Renard Perez, em seu Escritores brasileiros contemporâneos, $\operatorname{diz}$ que $A$ luz no subsolo

Marca mesmo inesperada reviravolta: é com o mundo introspectivo que se preocupa agora o romancista, através da sondagem da alma humana. O episódio, o descritivo da paisagem cedem lugar ao estudo do homem debatendo-se em seus conflitos íntimos (PEREZ, 1971, p. 232).

A análise de Perez confirma a escolha de Lúcio Cardoso de trilhar um caminho oposto àquele escolhido por grande parte dos escritores da época, os quais produziam uma literatura engajada socialmente e que se voltava, essencialmente, para a observação da realidade física e objetiva das pessoas.

Nelson Sodré, na obra Orientações do pensamento brasileiro, reconhece a alta carga dramática da obra de Lúcio Cardoso:

A sua força dramática se aviva e se intensifica no auge. No romance, Lúcio Cardoso chega a uma plenitude de expressão, a uma superioridade única e consegue fazer um livro diferente, um livro ímpar, não só pelas suas qualidades, mas pela sua feição, pela fisionomia que apresenta, pela maneira como foi composta a obra (SODRÉ, 1942, p. 182).

Essa carga dramática observada por Sodré faz com que o romance, embora constituído por personagens aparentemente alienadas, num hipotético cenário brasileiro da época, não se torne frio e descabido. Antes, a linguagem da narrativa aquece a trama, envolvendo-a por questões filosóficas que propiciam um mergulho ao cerne das motivações humanas. Em $A$ morte, os mortos e o morrer na Crônica da casa assassinada de Lúcio Cardoso (2007), Paulo Sergio Andrade Quaresma observa, a respeito do romance:

Nessa obra, por meio de um ambiente
desordenado e desorientador, impõe
às personagens a necessidade de
questionar e refletir sobre os motes
de seus íntimos e sobre os fenômenos
humanos sensíveis à curiosidade e ao
questionamento do homem: a razão da
vida, o sentido da morte, a existência de
Deus (QUARESMA, 2007, p. 41).

As obras de Lúcio Cardoso passam a receber dois possíveis tratamentos: ou eram ignoradas por completo, como se nunca tivessem sido lançadas, ou eram duramente criticadas. Sobre o assunto, 
Valéria Fernandes Lamego diz, em O conto e a vida literária de Lúcio Cardoso (19301950), que:

É a partir do livro rejeitado pela crítica refletido numa fortuna crítica pífia - que o autor se decide pelo escritor que hoje conhecemos. Mesmo com a adversidade de seu tempo, em que tantos escritores como críticos se guiavam pura e simplesmente pelas questões nacionais urdidas nas páginas literárias, ele trouxe o drama e o "clima de pesadelo" de um casal cindido pelo surgimento de um triângulo amoroso cujo vértice era uma jovem também disputada por um outro homem (LAMEGO, 2013, p. 37).

Cássia dos Santos, em sua obra Polêmica e controvérsia em Lúcio Cardoso, escreve que:

É importante deixar claro desde já que o romance representava, sem sombra de dúvida, uma reação consciente à literatura cultivada pelos nordestinos e provavelmente era o reconhecimento disto que estava por trás dos ataques que sofria (SANTOS, 2001, p. 33).

Sobre estes ataques referidos pela autora, entende-se, dentre outros, o artigo de jornal publicado em 20 de agosto de 1936 por Mário de Andrade, o qual manifestava dúvidas e desagrado sobre a obra cardosiana:

Que romance estranho e assombrado você escreveu! (...) Me deu um bruto de soco no estômago, fiquei sem ar, li, lia, o caso me prendia, os personagens não me interessavam [...] achei seu livro absurdo porque os personagens me pareceram absurdos [...] E não pareceram, não cheguei a senti-los como personagens de outros mundos. Loucos? Aberrados de qualquer realidade já percebida por mim? Ou antes criaturas exclusivamente criadas pelo autor para demonstrar sua percepção sutil e para mim um bocado confusa (não compreendi exatamente) da luz no subsolo? Tive mais a sensação que se tratava deste último caso (apud SANTOS, 2001, p. 31).

Sobre a posição de Mário de Andrade, pode-se pensar a análise de Maria Teresinha Martins:

Se as primeiras personagens da ficção cardosiana mal se davam conta de sua existência, e a vida passava-lhes praticamente desapercebida, a partir de A luz no subsolo habita-lhes tal intensidade anímica que não mais contém seus ímpetos (MARTINS, 1997, p. 49).

A loucura ou incompreensão percebidas por Mário de Andrade como possibilidades de leitura, possivelmente tratam dessa novidade colocada por Lúcio Cardoso no cenário da literatura nacional. Conforme citado anteriormente, as obras contemporâneas à A luz no subsolo aderiram ao recorte dito como regionalista e apresentavam, por conseguinte, características típicas ao movimento. A obra de Lúcio, por sua vez, rompe com esta corrente e apresenta personagens que explodem em intensidade anímica. Tal intensidade, não difusa com o espaço, mas com ele agente de ação e recepção da vida, caracteriza as personagens como incoerentes ou inimagináveis dentro do contexto de obras que vinham sendo produzidas no país.

É de se pensar, portanto, o estranhamento que sua obra causou no cenário literário da época. Conforme assinala Maria Terezinha Martins:

É óbvio em A luz no subsolo a opção deliberada pela arte sem compromisso com a função social. A realidade externa, o cotidiano, os fatores sociais tornam-se 
relevantes tão-somente quando se prestam à revelação, ao conhecimento íntimo das pessoas e da arte em si, ou seja, quando ocasionam o fazer literário (MARTINS, 1997, p. 13).

Mário Carelli, em Corcel de fogo: Lúcio Cardoso vida e obra (1912-1968), comenta sobre a recepção de Mário de Andrade acerca do romance cardosiano. $\mathrm{O}$ autor vê certa admiração nas palavras de Mário de Andrade, mas também destaca o desinteresse dele pelas personagens da obra:

A singularidade de A luz no subsolo é percebida fora do grupo de Lúcio Cardoso. Mário de Andrade fica desconcertado com a leitura do livro, mas se rende à evidência do novo caminho. As reticências do modernista são bastante compreensíveis. Os personagens lhe parecem psicologicamente arbitrários e politicamente alienados em relação ao clima que precede a Segunda Guerra Mundial (CARELLI, 1988, p. 33).

Ainda sobre o romance em questão, Álvaro Lins diz, em Os mortos de sobrecasaca, que:

A luz no subsolo, porém, não significa só um processo, mas uma nova vista. E de tal maneira que qualquer estudo sobre o Sr. Lúcio Cardoso terá que dividi-lo em duas fases distintas: antes e depois de A luz no subsolo. Antes: um romancista ligado a processos contrários ao seu temperamento; um autor indeciso e vacilante, ouvindo mais a voz dos outros do que a sua; um escritor que procura as suas formas de expressão, mantendo-se na superfície dos acontecimentos, das ideias, das paixões. Depois: um romancista de análise e de introspecção; um autor que se afirma com tendências dominantes do seu meio, procurando exprimirse com um máximo de sinceridade e de harmonia consigo mesmo; um escritor que nenhum preconceito e nenhum escrúpulo perturbam no seu propósito de revelar, em profundidade, as forças íntimas e mais desconhecidas que movimentam os homens, os seus sentimentos, os seus atos (LINS, 1963, p. 109).

Corroborando os fortes elogios de Álvaro Lins, Adonias Filho publica, em 1939, o texto Os romances de Lúcio Cardoso - Cadernos da hora presente (apud Braga Filho, 2008), onde diz:

A luz no subsolo (1936), livro que desce no interior da criatura para violar sentimentos e desvendar paixões, em sua natureza, em sua organização, antes de qualquer outra coisa, comprova a existência de um romancista livre de influências. Este romance assegura a Lúcio Cardoso um lugar autônomo, e um lugar autônomo na literatura do mundo (p. 77).

Em seu trabalho de dissertação "Os evadidos": Lúcio Cardoso e um trajeto do "ser" em A luz no subsolo (2009), Leonardo Grossi Alvarenga observa uma importante característica da escrita cardosiana: a "econômica" descrição física de suas personagens. É interessante notar que este elemento também se opõe, em certa medida, à corrente regionalista do nordeste à qual ele tanto se opunha. Lúcio Cardoso sempre privilegiou o enriquecimento interior de suas personagens, dando-lhes vida através de pensamentos, sensações, angústias, medos, indecisões, desejos, frustrações e autocrítica, em detrimento à explanação de seus aspectos físicos. Em A luz no subsolo, Madalena é descrita fisicamente como tendo "cabelos escuros e ondeados" (p. 14), "orelhas bem formadas" (p. 170) e "rosto pálido" (p. 245). Pedro é 
caracterizado com "corpo magro" (p.68) e "face pálida" (p. 141).

Na dissertação de Ana Karina Silva, Estética da angústia: uma leitura do romance "A luz no subsolo", de Lúcio Cardoso, ela escreve que "Em A luz no subsolo, os personagens tentam evadirse de uma determinada situação, como criaturas perseguidas pelo destino." (SILVA, 2012, p.66). Seguindo este pensamento, é possível identificar no romance, em especial em seus personagens, o instinto (animal) de preservação conflitante com a reflexão sobre temas transcendentes como a morte, Deus e o destino.

Se tudo o que Lúcio Cardoso produziu foi um "levantar-se contra Curvelo", conforme o próprio autor afirma em diversas entrevistas, a rejeição a um mundo superficial e atrasado foi o marco em seus romances.

Ferrenho investigador das questões da alma, Lúcio criou, através de seus textos, uma longa e tortuosa estrada pela qual passa o espírito humano enquanto busca razões sinceras para existir. Toda a produção literária de Lúcio Cardoso foi um enorme campo de batalha. Cada texto foi um movimento definitivo e sem retorno para alcançar seus objetivos.

No texto A presença do mal (2005), Mario Pontes fala que as obras de Lúcio Cardoso:

(...) eram barreiras destinadas a deter a vaga de materialismo que se espraiava sobre a cultura do século 20. Relato da destruição infernal de um mundo familiar que se torna insuportável, $A$ luz do subsolo é também um desses campos de batalha.

A partir destas questões até aqui levantadas, a análise a seguir objetiva investigar de que forma as personagens são configuradas ao longo da narrativa e como são estabelecidas as redes de relações entre elas.

\section{A personagem em A luz no subsolo}

Maria, primeira personagem a dar vida à trama, é apresentada como a prima pobre de Madalena. Maria é introduzida na história como um ser em desespero, avançando pelos espaços de sua mente e consumida pela incapacidade de desvencilhar-se de Madalena - embora seja extremamente necessário. O tempo surge como elemento que influencia diretamente na sua progressão dentro da trama. "Ficaria aqui a minha vida toda, mas..." (p. 17). Seja na sua imersão naquela vida abafada de agonias ou na imobilidade que a opressão Ihe causa, "ela permanecia ali, com a vaga consciência de que a manhã avançava" (p.9). A personagem se constitui no decorrer da história como uma criatura infeliz que vive um dilema muito forte: se, por um lado, ela não consegue abandonar Madalena, por outro, essa fuga mostra-se como a única chance de sua sobrevivência.

Com a introdução de Maria à trama, percebe-se que a opressão já está instaurada na vida daquelas pessoas que vivem em uma Curvelo distorcida e "extraordinária". Enquanto "Maria sentia, em tudo que a cercava, uma cruel correspondência com o seu espírito" (p.14), o espaço desdobra-se em sinais que alimentam a sua angústia. Adiante, na narrativa, Maria tenta aliar a possibilidade de livrar-se daquela angústia com o perdão de Madalena, como se precisasse de sua aprovação para viver em paz. O tempo e o espaço ressignificam a manhã em Curvelo, e enquanto a personagem constrói um 
discurso convincente para provar sua inocência frente aos mistérios e sofrimentos impostos naquela atmosfera, "ao mesmo tempo, a claridade fria do sol acentuava a sua lassidão" (p. 22).

Maria assume o papel de "única esperança de paz para Madalena" (p.60), uma vez que Madalena compreende a solidão que viverá nos próximos dias. Maria cria uma ruptura no sistema de vida do casal. Antes, Madalena conseguia viver iludida e cega pelo repelimento que Pedro instaurou entre eles. Após o anúncio da partida de Maria, Madalena não consegue mais fingir que seus sentimentos não são esmagados pela indiferença do outro, vendo em Maria a última chance de sua vida ir embora.

Cira surge na trama após Madalena ficar desestabilizada com a notícia de que Maria irá embora. Com a sensação de que toda a base com a qual estava acostumada a se escorar começará a ruir -- e que, com isso, revelar-se-á um mundo imperfeito e terminantemente obscuro - Madalena vai, desesperadamente, à casa de sua mãe, Camila, em busca de conforto.

Madalena é recebida por Cira, sua irmã, e esta é apresentada como uma bela mulher que "tinha uns cabelos magníficos que se desmanchavam em ondas fartas" (p.31). Cira é desenvolvida ao longo de toda a narrativa como uma personagem secundária e que viveu, sob vários aspectos, à sombra de Madalena. Desde a infância, Madalena parecia lidar muito bem com seu corpo e a feminilidade exigida socialmente, enquanto Cira sempre demonstrou dificuldades em estabelecer uma postura digna a apresentar-se socialmente. Numa das recordações de Madalena, num grande evento da cidade - uma passeata de uma missa que agregou todos os moradores de Curvelo -, é nítida a rememoração de sua beleza que causava encantamentos a todos, em contraponto à Cira: "Tinha bem nítida a figura irritada de Cira, que não conseguira a mesma harmonia e afogavase raivosamente num veludo cor de vinho debruado de rendas escuras" (p.42).

A mãe de Cira e Madalena é construída, sobretudo, pelos olhos de Madalena. Esta, ao buscar conforto e carinho na casa da mãe após receber a notícia da saída de Maria, frustra-se ao se deparar com uma criatura insossa e rude. De acordo com Madalena, "era preciso ter esquecido quem era aquela alma egoísta e fria, pregando eternamente teorias que a salvaguardassem de aborrecimentos causados pelos outros". Camila é uma personagem materialista, egóica e fútil que acredita que o dinheiro pode consertar qualquer problema. Seu pensamento é definido no trecho "o melhor é cortar tudo pela raiz". Afundada no alcoolismo, a personagem apresenta-se como a primeira sombra responsável por causar as chagas numa Madalena frágil e insegura. A caracterização da personagem segue o mesmo estilo da proposta elaborada em Cira, com maior importância aos seus atos. Madalena lembra da mãe como um ser corrompido pelo tempo e pela solidão. Só o que resta, aos olhos de Madalena, é "o vulto inquisidor de Camila, o copo de aguardente nos dedos cheios de anéis, os olhos aumentados por uma tinta violenta, brilhantes como os de uma criatura em febre" (p. 34).

A personagem Adélia é introduzida na segunda metade do romance, e sua inserção aumenta o clima de mistério da atmosfera romanesca. Sua caracterização inicial é feita sob o olhar de Pedro: "Vinha vestida de preto, com uma capa sobre os ombros, uma grande manta escura na 
cabeça" (p.151). Pode-se pensar Adélia como uma figura tomada pelos desejos malignos à medida que suas ações transgridem noções de honra e altruísmo. Mais do que uma criatura egoísta, a mãe de Pedro é configurada, sobretudo, no espaço da mansão do casal. O cenário alimentado por signos noturnos é ampliado nos encontros de Adélia no jardim, sob a luz das estrelas. Em uma de suas falas, Adélia diz: "Continuo sofrendo do mesmo modo. Entretanto, ouvi falar de pessoas que se alegram com o sol..." (p.167). Madalena observa o comportamento de Adélia e conclui: "era extraordinário que ela se apressasse a dar ordens" (p. 169). Essa tentativa de tomar o controle, por parte de Adélia, apresenta-se sob duas perspectivas: por um lado, a velha afronta o papel de Madalena na casa, dando ordens e fazendo escolhas que interferem na ordenação do sistema da casa; por outro lado, Pedro a odeia, fato que interfere constantemente nas tomadas de decisões e planos nefastos armados no interior da residência.

Bernardo terá duas grandes funções no romance: a primeira será de estabelecer uma relação de amor platônico por sua cunhada, Madalena, o que mais tarde acarretará numa importante guinada na vida dela; a segunda diz respeito à relação estabelecida com Pedro: o contato entre eles começará no segundo capítulo da obra e se estenderá até o desfecho do romance.

Se Maria representa a possibilidade de fuga e salvação para longe do local amaldiçoado pela maldade e obscuridade das pessoas, Emanuela reafirmará que o ambiente é capaz de ressignificar a vida de cada indivíduo levando-o a apenas dois possíveis caminhos: à loucura e ao sofrimento, ou à libertação. Prometida por Camila como a nova empregada que ajudará Madalena em casa, Emanuela é introduzida no romance ainda como a figura de uma jovem de dezenove anos que trabalha para ajudar a família. A primeira impressão de Madalena sobre a garota é de que "a sua voz era rouca, imprópria para uma criatura daquela idade" (p. 80). Essa primeira percepção já indica a inadequação de Emanuela às suas atitudes e aparência. Há uma atmosfera de mistério que ronda a personagem desde o início. Embora a primeira impressão sobre Emanuela não tenha deixado Madalena convicta a respeito de sua vinda para casa, a garota representará um novo fôlego para a esposa de Pedro (a primeira onda de ar puro desde a saída de Maria). A personagem trará vida e luz àquela casa mergulhada nas sombras e tocada pelo diabo. Sua presença na vida do casal fará com que lembranças sejam resgatadas: Ao mesmo tempo que a garota funciona como um filtro para os pensamentos obsessivos de Pedro e à angústia incurável de Madalena, Adélia e Bernardo, os infiltrados, tornar-se-ão figuras trevosas que rondarão seu pequeno quarto no jardim, com objetivos suspeitos.

Madalena é a personagem protagonista do romance, e, pode-se dizer, é um dos dois principais polos dos quais todas as outras personagens giram ao redor. Casada com Pedro, ela não consegue se conectar ao marido de forma alguma e sente que há diversas barreiras que os separam. Madalena é caracterizada como uma mulher com "angustiosa necessidade de ser amada" (p. 51). Madalena vive mergulhada nessa penumbra que a corrompe cada vez mais, com o desenrolar da narrativa. A personagem lida com uma espécie de "sabotagem interna" de maneira inconsciente. Ela não se permite buscar a luz (a felicidade), tampouco desafiar o 
marido. Ela "não tem a permissão de analisar seus sentimentos por Pedro" (p.61). Essa falta de permissão que ela assume fará com que, ao longo do romance, seja privada da capacidade de almejar alegrias e otimismo.

Madalena está sempre projetando uma vida em seus pensamentos. Uma vida que não combina com a realidade presente, que não se encaixa no que desejava em sua infância e que, certamente, não é o que precisa para o futuro. O futuro, aliás, é um conceito utópico para Madalena. Ela trilha um caminho solitário que não a desvencilha do elo com Pedro. Toda a vida da personagem é envolta na paralisia, e seu sofrimento espalha-se, como uma metástase, a cada elemento que a rodeia. Em dado momento ela nota: "mas olhando a estrada, percebera a solidão que envolvia todas as coisas" (p. 64). A solidão é a força implacável que a condiciona a esta nova prisão que se tornou sua vida.

Pedro representa o segundo polo principal da narrativa em A luz no subsolo. Se, por um lado, temos em Madalena o ponto de vista do oprimido, em Pedro temos um "lado B" da história: a angústia do desconhecido. A personagem poderia ser definida na passagem: "falo do coração envenenado pelas paixões... daquele que não tem coragem de recuar" (p.90). Ele detém o maior conhecimento, tanto no nível formal - ele é professor e está sempre imerso em leituras - quanto no nível de recursos intelectuais. Pedro é representado como uma personagem extremamente racional e introjetada em suas próprias ideias. Esta postura o afastou da sociedade e, por fim, da própria realidade. A personagem parece viver entediada. A vida cotidiana é vista como frivolidade e não o interessa. A leitura é utilizada como escudo
- protegendo-se dos outros, do mundo e de si próprio. Contudo, é com esta introspecção que a dor de Pedro progride, revelando uma personagem sem traços de altruísmo ou empatia.

Pedro, embora seja uma criatura desprovida de empatia, é dotado de um imenso magnetismo. Ele consegue modificar a visão que Madalena tinha sobre ele em poucos minutos. A atratividade que ele representa é revestida por um manto de mistérios que o desconhecido sempre veste. No romance, Pedro é o responsável por carregar os questionamentos que põem em dúvida a existência e o domínio das forças de Deus. Ele entende que nem todos são capazes de serem iluminados e, portanto, libertos. A vida é uma prisão para Pedro, mas é, sobretudo, uma prisão da razão, da lógica, da possibilidade de harmonia. E é vivendo sobre essa sombra que Pedro busca em Madalena a figura de Isabel - jovem e encantadora personagem da infância que foi cruelmente assassinada por ele. Segundo Mario Carelli (1988), a falta dessa luz que corrige, que liberta e que salva leva as pessoas a cometerem crimes brutais e atitudes desonrosas.

\section{A ilusão das relações}

Neste romance de Lúcio Cardoso, num primeiro momento, as personagens tendem a se revelar em suas formas individualizadas. Entretanto, ao longo da narrativa, elas passam a usufruir, silenciosamente, da companhia umas das outras - não que o aspecto individualizado suma de suas estruturas, mas o foco narrativo direciona a história para as relações que, pouco a pouco, serão consolidadas ou destruídas. Dessa forma, aqueles vínculos - préexistentes ou agora estabelecidos - serão 
os responsáveis por dinamizar a narrativa e ditar o tom para o processo de compreensão do texto.

Seja nos primórdios do surgimento da relação doentia do casal de protagonistas do romance, Pedro e Madalena, ou em seu presente processo de desunião, cada contato entre as personagens apresentado no decorrer do texto levará à exploração de novos e perigosos rumos - que, será visto, são irremediáveis. Por se tratar de redes de relações, o núcleo familiar não poderia deixar de estar sob o foco: Cira é uma mãe contraventora que não cede o colo afetuoso para as filhas; Camila é a irmã invisibilizada de Madalena; Bernardo é o cunhado com segundas intenções, e Adélia é a sogra que aquecerá ainda mais o antro pecaminoso do casarão de Curvelo.

Na relação entre Maria e Madalena, observa-se que Maria é a responsável por plantar a primeira semente de consciência em Madalena. A prima de Madalena é apresentada como uma figura fraca e oprimida pela presença de Pedro, e configura-se como tal no decorrer das poucas páginas nas quais é presente. No entanto, é a partir da desistência de Maria em viver na casa que Madalena parece sofrer o primeiro impacto de algo que até então vinha sendo mascarado: a presença perturbadora de Pedro.

Visto assim, então, Maria recebe uma nova configuração quando analisada em relação a Madalena: percebe-se força em seu interior para ser capaz de livrar-se do mal daquela casa e, concomitantemente, impulsionar Madalena a desbravar a vida e seus reais interesses. Há, ainda, um sentimento de culpa pela parte de Maria, com a decisão de ir embora: "A suposição de que Madalena também pudesse sofrer fizera Maria esconder o rosto nas mãos, sem saber o que dissesse" (p. 16-17).

Adélia, Pedro e Bernardo formam uma das principais redes de relações no romance, na qual um influencia no futuro do outro desde o primeiro momento de suas relações. Pedro, assim como Madalena, é um dos elementos catalisadores do romance. Quase todas as vozes ecoam até seus ouvidos, e seu olhar alcança os extremos do romance. Todas as personagens, mesmo que de forma indireta, parecem agir de maneira a corroborar com a descoberta de Pedro sobre si próprio. E esse processo de revelação é sombrio e perturbador. Ao analisar a trajetória de Pedro ao longo da narrativa, percebe-se que há dois pilares fundamentais para o apoio de suas ações pecaminosas: Adélia, sua mãe, e Bernardo, cunhado de Madalena.

Adélia parece funcionar como uma peça que resgata a ancestralidade de Pedro e justifica seus pensamentos assombrosos. A péssima relação estabelecida entre mãe e filho parece tentar despertar alguma compaixão no leitor por Pedro. Adélia é uma velha amarga, rígida, solitária. Parece retirada de algum conto de fadas no qual ela certamente representaria uma bruxa. Essa imagem fortemente antagônica no romance é construída de forma a explicar o perfil de Pedro, ao mesmo tempo em que serve como empecilho para o empoderamento de Madalena.

Pedro e Bernardo mantêm uma relação próxima desde o início da narrativa. Os diálogos entre eles, entretanto, parecem ser uma forma de autorreflexão utilizada por Pedro. O marido de Madalena parece não considerar, realmente, a presença de Bernardo como significante ou ameaçadora. Outrossim, Bernardo é apenas um pretexto para que o processo introspectivo de 
Pedro intensifique-se e alcance patamares irremediáveis. No entanto, a influência maléfica de Pedro atinge Bernardo desde o início. O incômodo frente a Pedro é inquestionável. Enquanto este elabora uma série de provocações e indagações que desafiam a força e existência de Deus, aquele é hipnotizado pelos devaneios do professor. Também se faz fundamental ressaltar que o cunhado de Madalena é atraído pela força magnética natural de Emanuela, e essa atração funciona como o argumento que faltava para desestabilizálo por completo, impulsionando-o à agressividade.

Adélia e Pedro possuem ligações que transcendem os laços sanguíneos. Ambos são personificações do próprio mal. Nenhuma de suas camadas revela uma atitude generosa ou bondosa. Desse modo, pode-se pensar na figura de Adélia como a primeira a consolidar a maldade, fato que foi passado maternalmente para Pedro. A presença de Adélia no romance contribui para que Pedro desvincule-se da realidade. Ele não consegue mais fixar-se na vida: sua mente é preenchida por devaneios filosóficos incapazes de serem respondidos. Com isso ocorre um desdobramento da personalidade de Pedro, ao longo da narrativa, que pode ser relacionado a uma forma de pedir socorro, ou, em última instância, simbolizar sua derrota frente a uma vida consumida pela incompreensão e pelo medo.

Entre Pedro e Emanuela é estabelecida uma relação de caça e caçador. Emanuela lembra uma figura do passado de Pedro, o que reacende seu jeito perseguidor. Além disso, Pedro é ressignificado, no decorrer de suas interações com Emanuela, chegando a representar a figura de um abusador, psicopata e doente. A menina desperta no marido de Madalena o que há de pior em sua alma penumbrosa. Ela é a chave da porta de sua consciência, e, uma vez aberta, a passagem para a alucinação e o insólito nunca mais se fecham.

Pedro e Madalena constituem a principal relação de $A$ luz no subsolo. Eles são como dois planetas cujas forças magnéticas os atraem, mas as atmosferas são incapazes de conviverem muito próximas, gerando, imediatamente, o repelimento entre ambos. Há uma força que os atrai para um destino irremediável. Todo o universo de Curvelo habita a relação do casal, e, pode-se dizer, é a partir dos dois que surgem todas as linhas que atam as demais personagens. Em dado momento, Madalena, através do narrador, se questiona "por que aquele homem retinha todos os seus movimentos...?" (p. 27).

As personagens não almejam propriamente a totalidade pois cada parcela de seus anseios é o suficiente para que elas compreendam a limitação humana. Consciente desta condição inacabada, Madalena não tenta encontrar a resposta para seus pavores em Pedro. Há uma tomada de consciência na personagem que faz com que ela passe a ver o marido como uma criatura repelente e mesquinha. $\mathrm{O}$ anseio, neste caso, gira em torno da sua incapacidade de largar essa condição de dependência pré-estabelecida na relação. Madalena depende de Pedro, ainda que os sentimentos por ela alimentados não sejam mais do que uma mera ilusão do que ela gostaria que fossem.

Deve-se pensar, por isso, na relação das personagens com os objetos que compõem o meio: Pedro está terminantemente vinculado aos livros. A leitura é ressignificada como método de fuga e, mais do que isso, representa um campo de força 
intransponível para Madalena. Esse fator cultural representa para Madalena uma mania que só serve para aumentar a distância entre eles.

Em seu Diário O, Lúcio Cardoso escreve:

Qualquer descrição moral do mundo será limitada e estúpida. As descrições do mundo só são possíveis por meio de "concepções" generalíssimas que, explicando tudo, nivelam tudo, arrasam tudo (CARDOSO e RIBEIRO, 2012, p. 102).

Inseridos nesta atmosfera que oprime e assola, as personagens de A luz no subsolo não conseguem sustentar vínculos reais nem com seus parentes mais próximos. O amor é devastado pela inaptidão do carinho e da compreensão. Os sentimentos são obscurecidos pelas vaidades.

Há um mundo particular que vive no subsolo de cada criatura. É lá que as personagens estão aprisionadas. É num reduto muito íntimo - mas, ironicamente, globalizado - que cada ser resguarda suas maiores paixões. E é neste fogo, no qual ardem os sentimentos mais violentos, que a luz da salvação perde o brilho, enfraquece e se distancia, cada vez mais, da realidade.

Todos, como um rebanho, presos na imensidão de suas próprias ânsias, descobrirão que não há nada mais ilusório do que a perfeição da vida.

\section{Referências}

abBaGnanO, N. Dicionário de filosofia. 3. ed. São Paulo: Martins Fontes, 1998.

ARAúJO, B. Crônicas da casa assassinada: reflexões acerca do espaço literário e de leitura. Revista Leitura, v. 2 n. 54 (Leituras interartes), jul./ dez. 2014.
AVARENGA, L. "Os evadidos": Lúcio Cardoso e um trajeto do "ser" em A luz no subsolo. Dissertação (Mestrado) - Pontifícia Universidade Católica de Minas Gerais, Belo Horizonte, 2009.

BANDEIRA, M. Carta, 17 de janeiro de 1939 a Lúcio Cardoso.

BOURNEUF, R.; OUELLET, R. O universo do romance. São Paulo: Almedina, 1976.

BRAGA FILHO, J. A melancolia narrada: Dias perdidos, de Lúcio Cardoso. Dissertação (Mestrado) - Universidade Federal do Paraná, Curitiba, 2008.

BRANDÃO, R. (Org.). Lúcio Cardoso: a travessia da escrita. Belo Horizonte: Editora da UFMG, 1998.

CANDIDO, A. A personagem de ficção. São Paulo: Perspectiva, 1972.

CARDOSO, E. Seres predestinados ao mal: as personagens femininas e a família na prosa de Lúcio Cardoso. Angulo, p. 121-122, abr./set., 2010.

CARDOSO, L. A luz no subsolo. Rio de Janeiro: Civilização Brasileira, 2003.

CARDOSO, L. A crônica da casa assassinada. São Paulo: José Olympio, 1959.

CARDOSO, L.; RIBEIRO, E. (Org.). Diários. Rio de Janeiro: Civilização Brasileira, 2012.

CARDOSO, L. Maleita. Rio de Janeiro: Schmidt, 1934.

CARDOSO, L. Mãos vazias. São Paulo: José Olympio, 1938.

CARDOSO, L. Salgueiro. São Paulo: José Olympio, 1935.

CARELLI, M. Corcel de fogo: Lúcio Cardoso vida e obra (1912-1968). Rio de Janeiro: Guanabara, 1988.

COUTINHO, A. (Dir.). A Literatura no Brasil. 2. ed. Rio de Janeiro: Sul-Americana, 1970. Vol. V: Modernismo.

FILHO, A. Os romances de Lúcio Cardoso. In: Cadernos da hora presente, n. 4, 1939.

FORSTER, E. M. Aspectos do romance. Porto Alegre: Globo, 1974.

HAMON, P. Le Personnel du roman. Genève: Droz, 1983.

LAMEGO, V. O conto e a vida literária de Lúcio Cardoso (1930-1950). Tese (Doutorado) Pontifícia Universidade Católica do Rio de Janeiro, Rio de Janeiro, 2013.

LINS, A. Os mortos de sobrecasaca. Rio de Janeiro: Civilização Brasileira, 1963. 
MARTIN, M. T. Luz e sombra em Lúcio Cardoso. Goiânia: Editora da UFG, 1997.

MORAIS, F. Lúcio Cardoso, Cornélio Penna e a retórica do Brasil profundo. Dissertação (Mestrado) - Universidade Federal de Ouro Preto, Mariana, 2015.

MUIR, E. A estrutura do romance. Porto Alegre: Globo, 1975.

PAIXAO, R. Quando a arte imita a vida: ficção e memória nos diários de Lúcio Cardoso e Walmir Ayala. Dissertação (Mestrado) - Universidade Federal de São João del-Rei, São João del-Rei, 2011.

PEREZ, R. Escritores brasileiros contemporâneos. Rio de Janeiro: Civilização Brasileira, 1971.

PONTES, M. A presença do mal. In: JB Online. Acesso em: 15 ago. 2016.

RIBEIRO, E. Riso escuro ou pavão de luto. São Paulo: EDUSP, 2006.

QUARESMA, P. A morte, os mortos e o morrer na Crônica da casa assassinada de Lúcio Cardoso. Dissertação (Mestrado) - Fundação Universidade de Rio Grande, Rio Grande, 2007.

REIS, C. O conhecimento da literatura: introdução aos estudos literários. Porto Alegre: Edipucrs, 2003.
REIS, C.; LOPES, A. C. Dicionário de narratologia. Coimbra: Livraria Almedina, 1987.

SANTOS, C. Polêmica e controvérsia em Lúcio Cardoso. Campinas: Mercado de Letras, 2001.

SILVA, A. Estética da angústia: uma leitura do romance "A luz no subsolo", de Lúcio Cardoso. Dissertação (Mestrado) - Pontifícia Universidade Católica do Rio Grande do Sul, Porto Alegre, 2012.

SODRÉ, N. Orientações do pensamento brasileiro. Rio de Janeiro: Vecchi, 1942.

SOUSA, P. A manifestação do grotesco nos romances de Lúcio Cardoso. Dissertação (Mestrado) - Universidade Federal de Minas Gerais, Belo Horizonte, 2013.

TIBURRI, A. Atmosfera de paixão e tempestade: as dimensões do espaço ficcional na Crônica da casa assassinada, de Lúcio Cardoso. Dissertação (Mestrado) - Universidade de Caxias do Sul, Caxias do Sul, 2013.

WARREN, A.; WELLEK, R. Teoria da literatura. Lisboa: Europa-America, 1972.

Recebido: 6 de junho de 2017. Aceite: 4 de agosto de 2017 